\title{
Hydrothermal Carbonization of Seaweed For Advanced Biochar Production
}

\author{
Tirto Prakoso ${ }^{1 *}$, Rima Nurastuti $^{1}$, Reza Hendriansyah $^{1}$, Jenny Rizkiana ${ }^{1}$, Gede Suantika ${ }^{2}$, Guoqing Guan ${ }^{3}$ \\ ${ }^{1}$ Departement of Chemical Engineering Institut Teknologi Bandung 40132 Indonesia \\ ${ }^{2}$ School of Life Sciences and Technology Institut Teknologi Bandung 40132 Indonesia \\ ${ }^{2}$ North Japan Research Institute for Sustainable Energy, Hirosaki University, Aomori 030-0812 Japan
}

\begin{abstract}
Seaweed such as Eucheuma Cottonii is a potential source of biomateriallts high moisture content makes it suitable for hydrothermal conversion process since it doesn't need to utilize dry feedstock. The aim of this study is to convert the biomass of red seaweed Eucheuma Cottonii into alternative fuels and high value biomaterials using hydrothermal process. The hydrothermal process seaweed Eucheuma Cottonii produce two types of products, liquid product and char (solid). This research focus on the char product. The char from hydrothermal process was then activated using the tubular furnace. The yield for activated char is $7.5 \%$ and results of SEM analysis of activated char showed the formation of allotropes carbon include carbon micro spheres, carbon micro fibres and graphene. These structures have encountered application in a wide range of technological fields, such as adsorption, catalysis, hydrogen storage or electronics.
\end{abstract}

\section{Introduction}

United Nation Convention on the Law of the Sea (UNCLOS) in 1982 reported that Indonesia marine teritority ocupied 5.8 million $\mathrm{km}^{2}$ and it contains $27.2 \%$ of all species flora and fauna from all over the world. Seaweed or known as macroalgae is one of the most abundant biological resources in Indonesian, which is about $8.6 \%$ from the total biota in the sea [1]. The habitat of seaweed in Indonesia reaches 1.2 million hectares and it is considered as the largest seaweed habitat in the world [1].

Abundant aviablity of seaweed in Indonesia should be optimized by turning this resources into other high value product. Some of product that can be obtained from seaweed are biomaterial and biofuel. Seaweed conversion into biomaterial and biofuel by hydrothermal process has drawn much attention. Hydrothermal process take place in water at high temperature ranging at 250$347^{\circ} \mathrm{C}$ and pressure ranging at $4-22 \mathrm{MPA}$. The most advantages of hydrothermal process is it can use feedstock with high moisture content without the need of pre-dying [2]. Therefore, hydrothermal process is suitable to be used for seaweed processing since it has high moisture content.

Hydrothermal process produced three main products such as bio-gas, bio-oil, and bio-char. These products can be obtained by tuning the temperature of hydrothermal process. Bio-char as a main product from hydrothermal process obtained when temperature process tuned at $150-275^{\circ} \mathrm{C}$. Meanwhile for bio-oil purposes hydrothermal temperature tuned above $275^{\circ} \mathrm{C}$. Furthermore in this research is focused on development of seaweed into biomaterial and biofuel products via hydrothermal process.

\section{Experimental}

In this present research, hydrothermal carbonization was performed in hydrothermal reactor equipped with heater. Eucheuma Cottonii was chosen as biomass sample and then dried biomass were choped into $1 \mathrm{~cm}$ long.

Biomass precursor was mixed with water in mass ratios of 1:20, 1:10 and 1:5. Hydrothermal reactor was then heated to $250-275^{\circ} \mathrm{C}$ and held for $30-90$ minutes. After cooling process, bio-char and bio-oil were separated by filtration and bio-char dried at $105^{\circ} \mathrm{C}$ for 24 hours.

The bio-char recovered from hydrothermal process was then treated by $\mathrm{CO}_{2}$ activation method to activate the char. Bio-char was loaded onto crucible and positioned inside the tubular furnace. Temperature of furnace ramped to $800^{\circ} \mathrm{C}$ at a rate $10^{\circ} \mathrm{C} / \mathrm{min}$ in the presence of $\mathrm{N}_{2}$ at flow rate of $50 \mathrm{ml} / \mathrm{min}$. After the final temperature was reached, $\mathrm{N}_{2}$ then replaced by $\mathrm{CO}_{2}$ at a flow rate of $40 \mathrm{ml} / \mathrm{min}$ and held for 2 hours.

The solid product was characterized by several methods. Ultimate and proximate analysis were

Corresponding author: tirto@che.itb.ac.id 
conducted in Laboratorium Pengujian Batubara tekMIRA Bandung to determine the chemical and physical characteristics of biomass. FT-IR analysis were carried out in quantitative and qualitataive estimation of oxygen-containing functional groups. Surface area of bio-char and activated carbon were obtained by using a gas sorption Quantochrome Instruments Nova 3200e conducted in Laboratorium Instrumentasi Teknik Kimia ITB. The morphology of activated carbon were examined by Scanning Electron Microscopy (SEM) using SEM Hitachi SU3500 conducted in Pusat Penelitian Nanosains dan Nanoteknologi Institut Teknologi Bandung. As for the liquid products, it was evaporated in a vacum evaporator to separate the water from the bio-oil prior characterization using GC-MS.

\section{Result and discussion}

\subsection{Seaweed characterizations}

Table 1 shows the proximate and ultimate analysis of Eucheuma cottonii. The elemental composition of the seaweed obtained from ultimate analysis. It is observed that the seaweed had high oxygen and carbon content. The seaweed had a biger proportion of volatile matter than fixed carbon, moisture and ash. Moreover, the seaweed had a high ash content comparing to other biomass due to the alkali content from this seaweed was high [3]. Since it has high ash content, the thermochemical process such as direct combustion, pyrolysis, and gasification was not suitable for this seaweed. However this characteristics was more acceptable when hydrothermal process being used [4].

Table 1. Proximate and Ultimate analysis of Eucheuma Cottonii.

\begin{tabular}{|c|c|}
\hline \multicolumn{2}{|c|}{ Proximate (\%) } \\
\hline M & 11.2 \\
\hline VM & 47.4 \\
\hline FC & 27.82 \\
\hline Ash & 13.58 \\
\hline Ultimate (\%) \\
\hline C & 21.11 \\
\hline H & 4.26 \\
\hline N & 0.35 \\
\hline O & 57.73 \\
\hline S & 2.97 \\
\hline
\end{tabular}

\subsection{Solid product (bio-char)}

Table 2 shows the bio-char obtained after hydrothermal process. In General io-char obtained from hyrothermal process decreased when holding time of hydrothermal process was set longer. The longer holding time increases reaction severity so that bio-char obtained after hydrothermal process decreased [5]. Furthermore, the decrease of bio-char was attributed to devolatilization of volatile matter within the biomass precursor [6].

However, some samples showed the opposite. Longer residence time resulted in a higher bio-char produced. it was expected due to secondary char formation of polyaromatic char from non-dissolved lignin content. It can be seen that bio-char produced after hydrothermal process decreased while hydrothermal process temperature increased.

The decreased of bio-char produced was expected due to primary decomposition of biomass and secondary decomposition of char residue at higher temperature [7]. Some of samples observed produced more bio-char while hydrothermal process temperature increased. This phenomena was expected due to secondary char formation caused by extensive condensation/intermolecular dehydration and formation of polymers [8]. This phenomena was also found when the biomass to water ratio decreased, causing the biochar produced increased. The increased of bio-char produced was expected due to polimerization becomes dominant so that the dissolved monomer of decomposed products formed solid phase products [8].

Table 2. Bio-char produced after hydrothermal process (g).

\begin{tabular}{|c|c|c|c|}
\hline Biomass:water ratio & \multicolumn{3}{|c|}{$1: 20$} \\
\hline Holding (min) & 30 & 60 & 90 \\
\hline $250^{\circ} \mathrm{C}$ & 8.6 & 5.72 & 6.7 \\
\hline $275^{\circ} \mathrm{C}$ & 10.78 & 5.89 & 4.64 \\
\hline Biomass:water ratio & \multicolumn{3}{|c|}{$1: 10$} \\
\hline Holding (min) & 30 & 60 & 90 \\
\hline $250^{\circ} \mathrm{C}$ & 13.35 & 13.49 & 13.09 \\
\hline $275^{\circ} \mathrm{C}$ & 12.89 & 12.99 & 9.69 \\
\hline Biomass:water ratio & & $1: 5$ \\
\hline Holding (min) & 30 & 60 & 90 \\
\hline $250^{\circ} \mathrm{C}$ & 24.55 & 24.645 & 25.145 \\
\hline $275^{\circ} \mathrm{C}$ & 23.935 & 19.04 & 16 \\
\hline
\end{tabular}

Figure 1. shows the comparison of FT-IR spectrun from raw seaweed, bio-char and bio-oil which obtained from hydrothermal process. Peak around $\sim 3500 \mathrm{~cm}^{-1}$ represents $\mathrm{O}-\mathrm{H}$ bonds from alcohol, fenol and carboxyl functional groups. The intensity of $\mathrm{O}-\mathrm{H}$ bond in bio-char decreased after hydrothermal process compared to raw seaweed due to dehydration of the raw seaweed occured so that water molecules within the biomass decreased [9]. Meanwhile, the intensity of $\mathrm{O}-\mathrm{H}$ bond in bio-oil sample greater than the others due to it has high amount of water content. The peak around $\sim 2900 \mathrm{~cm}^{-1}$ attributed to aliphatic groups $\left(\mathrm{CH}_{\mathrm{n}}\right)$. The intensity of this peak in bio-char decreased compared to raw seaweed after hydrothermal process, indicating some of aliphatic long 
chain broke down [9]. Peak around $\sim 1600 \mathrm{~cm}^{-1}$ represnted the $\mathrm{C}=\mathrm{C}$ bonds was attributed to aromatic ring of lignin and aromatic groups formed during hydrothermal proces [10]. The decreased of intensity around $\sim 1600 \mathrm{~cm}^{-1}$ indicated the removal of inorganic carbonate from raw materials [10]. The peak around $\sim 1000 \mathrm{~cm}^{-1}$ represented the $\mathrm{C}-\mathrm{O}$ bond, the intensity of this bond decreased after hydrothermal process due to breaking $\mathrm{C}-\mathrm{O}$ linkages during hydrothermal process [10].

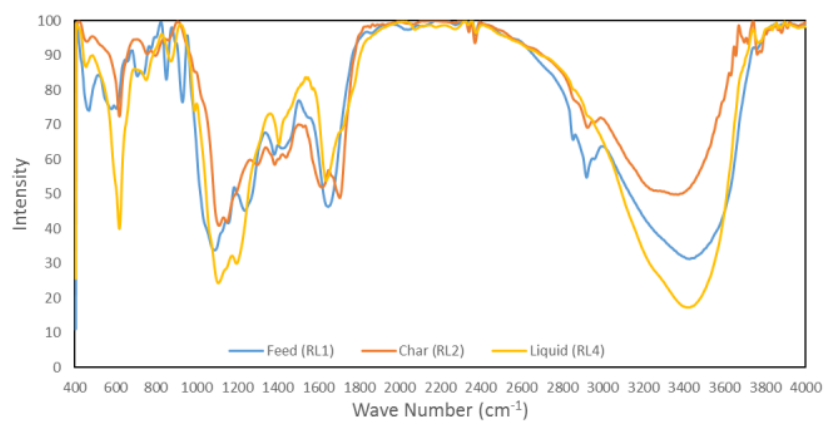

Fig. 1. FT-IR spectrum of raw seaweed and bio-char.

These bio-char could be further applied for various applications such as solid fuel, soil enrichment, catalysis, water purification, energy storage, and $\mathrm{CO}_{2}$ sequesterian. As solid fuel and soil enrichment these bio-char could applied directly without further modification. Commonly for catalysis, water purification, energy storage and $\mathrm{CO}_{2}$ sequesterian applications these bio-char further treated by thermal, chemical, or pyhsical activation to improved the characteristic of the carbonaceous materials, by turning these bio-char into activated carbon. The desired characteristic of activated carbon furthermore could be tuned by changing the parameter process of activation process [11].

\subsection{Liquid product (bio-oil)}

Bio-oil from hydrothermal process at $275^{\circ} \mathrm{C}$ and holding time 30 minutes was chosen for GC-MS analysis. Liquid product or bio-oil obtained after separation process was evaporated to reduce the water content of the bio-oil. The residue from evaporation were water and concentrated bio-oil. The concentrated bio-oil afterwards diluted on aceton for bio-oil aceton ratio was 1 to 100 . This diluted bio-oil then injected to GC-MS to analyze the composition of bio-oil. The result from GCMS analysis shown in Table 3.

It can be seen that most of the compounds indentified from bio-oil were alkanes, aromatic, alcohol and organic acid. Toluene was the compound of highest content, contributing $63,01 \%$ of the total area followed by benzene which contributing $14,53 \%$ of the total area. Only one organic acid, levulinilic acid and one alcohol, diacetone alcohol were detected. During the hydrothermal process lignocelullosic biomass first hydrolyzed and leads to form polyscharides, afterwards this polyscharides hydrolyzed into glucose and some might go further to form fructose. The decomposition of theses glucose and fructose leads to the formation of organic acids such as levulinic acid $[8,12]$. The aromatics compounds detected in bio-oil such as benzene and toluene was expected formed via intermolecular dehydration of aromatic compounds derived from lignin [8]. The present of lipid in algae contains saturated and unsaturated fatty acids, which is derived from triglyceride hydrolysis. It was expected that the present of small amount of alkanes in bio-oil were formed from decarboxylation reaction of fatty acid presented in algae $[13,14]$.

Table 3. Chemical detected in bio-oil from GC-MS analysis.

\begin{tabular}{|c|c|c|c|}
\hline Number & $\begin{array}{c}\text { Retention } \\
\text { Time }\end{array}$ & Area $\%$ & Name \\
\hline 1 & 2.18 & 14.53 & Benzene \\
\hline 2 & 2.307 & 1.31 & Cyclopentane \\
\hline 3 & 2.341 & 1.39 & Heptane \\
\hline 4 & 2.541 & 6.28 & Methylcyclohexane \\
\hline 5 & 2.821 & 3.18 & 2,5 -Dimethylhexane \\
\hline 6 & 2.889 & 63.01 & Toluene \\
\hline 7 & 2.981 & 1.82 & $\begin{array}{c}\text { cis-1,3 } \\
\text { Dimethylcyclohexane }\end{array}$ \\
\hline 8 & 3.17 & 2.45 & Cyclohexane \\
\hline 9 & 3.623 & 4.71 & Diacetone alcohol \\
\hline 10 & 6.39 & 1.31 & Levulinic acid \\
\hline
\end{tabular}

\subsection{Post modification of bio-char}

Bio-char from hydrothermal process at $250^{\circ} \mathrm{C}$ and holding time 30 minutes was chosen for activation process. Solid product or bio-char obtained after separation process was loaded into tubular furnace and heated at $800^{\circ} \mathrm{C}$ for two hours in $\mathrm{CO}_{2}$ atsmosphere. Figure 2. Shows the comparison of SEM images from raw seaweed and activated carbon. SEM image of Fig 2. (a) shows the morphology of raw seaweed before sequentally treatment. It can be seen that morphology of raw seaweed has irregular shape like block and closed surface. Fig 2. (b) and (c) shows the differences of raw seaweed and activated carbon. After actvation process it observed that activated carbon has some morphological shapes. Fig 2. (b) and (c) shows that activated carbon composed of agglomerates of spherical particles like microspheres and long structure like fiber. This structure was probably generated as a consequence of the sequentially treatment that given to the raw seaweed and also affected from characteristics of raw seaweed. 


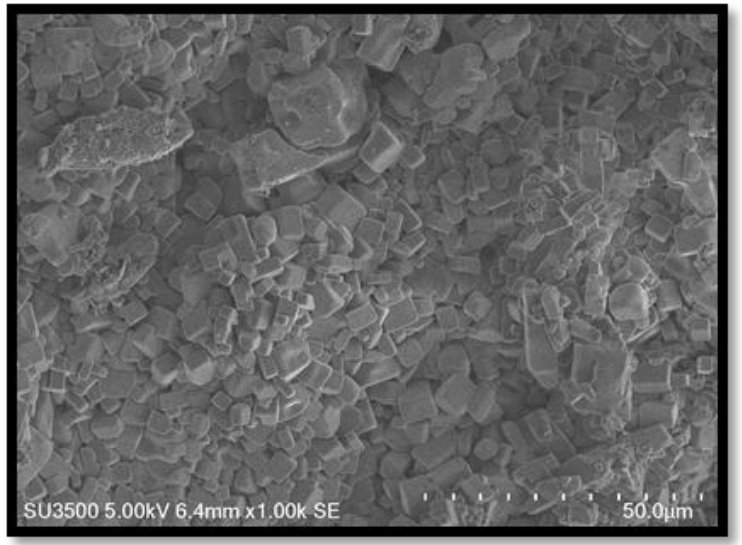

(a)

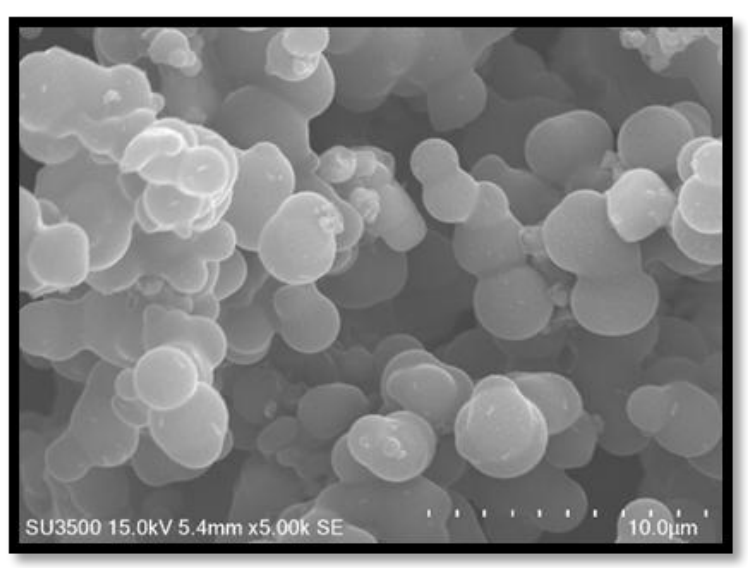

(b)

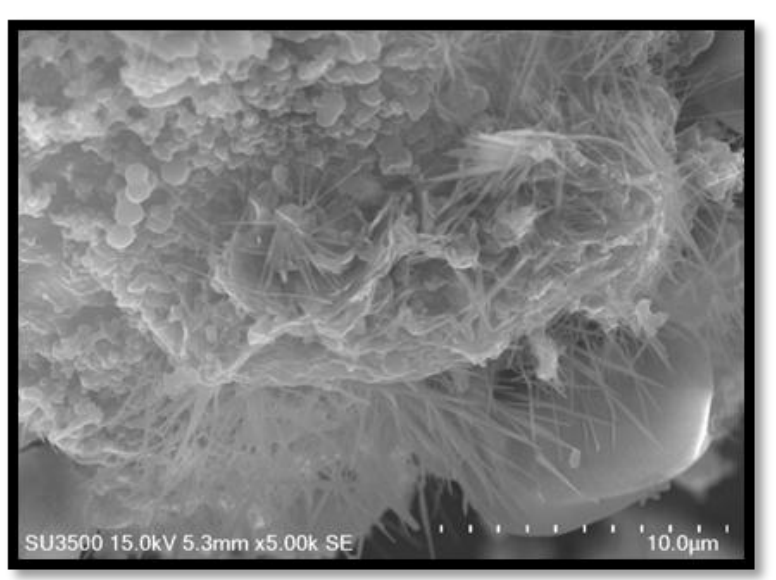

(c)

Fig. 1. SEM images of (a) raw seaweed (b) activated carbon (c) activated carbon.

Table 4 shows the comparison of surface area of activated carbon obtained from this research and commercial activated carbon. It can be seen that comercial activated carbon has greater surface area than synthesized activated carbon and also the gaps between these samples was very significant. Adding activating agent during hydrothermal process could enhance the porosity of the material. Sevilla et al. [16] added $\mathrm{KOH}$ as activating during hydrothermal process to produce highsurface area carbons up to $2700 \mathrm{~m}^{2} / \mathrm{gr}$ from furfural, glucose, starch, cellulose and eucalyptus sawdust. Meanwhile Wang et al. [17] demonstrated the production of high-surface area carbons that can be reached up to $2610 \mathrm{~m}^{2} / \mathrm{gr}$ using $\mathrm{H}_{3} \mathrm{PO}_{4}$ as activating agent during the hydrothermal process. Based on those results, the improving the porosity of the activated carbon could be done by adding activating agent during the hydrothermal process.

Table 4. Surface area of synthesized activated carbon and comercial activated carbon.

\begin{tabular}{|c|c|}
\hline Sample & Surface Area $\left(\mathrm{m}^{2} / \mathrm{gr}\right)$ \\
\hline Synthesized Activated Carbon & 12.35 \\
\hline Comercial Activated Carbon & 832.967 \\
\hline
\end{tabular}

From the result obtained, carbon microspheres and carbon nano fibers could be applied as materials for supercapacitors electrode. Carbon microshperes offered several advantages such as have regular morphology, adjustable porosity, and particle size causing the resistance of ion diffusion decrease and improved the electrochemical performance while applied as materials for supercapacitor electrode [18] (Zhu et al., 2015). Meanwhile carbon nano fiber gives several advantages such as tunable surface functionalities, dimensional stability, and transport property [19] (Jang et al., 2005).

\section{Conclusion}

Utilization of seaweed by hydrothermal process has a great potential to be an alternative process for production of wide variety products. Furthermore, the product obtained from hydrothermal process such as bio-char and bio-oil could be applied for various applications. However the further investigation is still needed for product and process development so that the characteristic of product can be specialized to specific applications. From the result achieved of this research, the bio-char obtained should be more developed by adding chemical on hydrothermal process to enhanced the porosity of activated carbon and the activated carbon produced could be applied as material for supercapacitor electrode.

\section{Acknowledgment}

This work is supported by Program Insentif Riset Sistem Inovasi Nasional (Insinas) 2016. 


\section{References}

1. Suparmi, Sahri, Achmad., Sultan Agung Vol XIV 96, 118 (2009)

2. K. Tekin, S.Karagöz, \& S. Bektaş, , Renew. Sustainable Energy Rev., 40, 673-687 (2014)

3. Smith, M. Aidan, Ross, B. Andrew,Algal Res, 16, 111 (2016)

4. Q. Xu, Q.Qian, A. Quek, N. Ai, G. Zeng, , J. Wang, ACS Sustainable Chem. Eng 1, 1092-1101 (2013)

5. A. Funke, \& F. Ziegler, Biofpr 4, 160-177 (2010)

6. He, C., Giannis, A., \& Wang, J. Y., Appl. Energy 111, 257-266 (2013)

7. N. M. Nor, L. C. Lau, K. T. Lee, \& A. R. Mohamed, , JECE 1, 658-666 (2013).

8. A. Jain, R. Balasubramanian, \& M. P. Srinivasan, Chem. Eng. J. 283, 789-805 (2016)

9. A. T. Yuliansyah, T.Hirajima, Waste and Biomass. Valori. 1, 395-405 (2010)

10. S. Nizamuddin, J. Kumar, , Subramanian, N., Sahu, J. N., Ganesan, P., N. M. Mubarak, \& S. A. Mazari,, Can. J. Chem. Eng. 93, 1916-1921 (2015)

11. M. M. Titirici, R. J. White, C. Falco, \& M. Sevilla, Energ. Environ. Sci. 5, 6796-6822 (2012)

12. M. T. Reza, J. Andert, B.Wirth, D. Busch, J. Pielert, , J. G. Lynam, \& Mumme, J., Appl. Bioenerg. , 1 (2014)

13. Y. Guo, T. Yeh, W. Song, D. Xu, \& S. Wang, , Renew. Sustainable Energy Rev. 48, 776-790 (2015)

14. L.Hadhoum, M. Balistrou, G.Burnens, K.Loubar, \& M. Tazerout, , Bioresour. Technol. 218, 9-17 (2016)

15. P. Matanjun, S. Mohamed, N.M. Mustapha, Muhammad, K., J of Appl Phycol 21, 75-80 (2009)

16. M. Sevilla, A. B.Fuertes, \& R. Mokaya, Energ. Environ. Sci. 4, 1400-1410 (2011)

17. L.Wang, Y Guo, B. Zou, C.Rong, X.Ma, Y.Qu, \& Z. Wang, Bioresour. Technol, 102, 1947-1950 (2011)

18. D. Zhu, Y.Wang, L.Gan, Liu, M., K Cheng, Y. Zhao, \& D. Sun, Electrochim. Acta, 158, 166-174 (2015)

19. J. Jang, J. Bae, M. Choi, \& S. H. Yoon, Carbon, 43, 2730-2736 (2005) 